\title{
A Integração de Saberes e as Marcas dos Conhecimentos Tradicionais: Reconhecer para Afirmar Trocas Interculturais no Ensino de Ciências
}

\section{The Integration of Knowledge and the Marks of Traditional knowledge: Recognizing to Affirm Intercultural Exchanges in Science Teaching}

\author{
Rodrigo dos Santos Crepalde \\ Verônica Klepka \\ Tânia Halley Oliveira Pinto \\ Mikaella de Sousa \\ Brasil \\ Brasil \\ Brasil \\ Brasil
}

O texto apresenta, analisa e discute algumas marcas/características presentes nos conhecimentos tradicionais relacionados à influência da Lua em práticas sociais de camponeses mapeados etnograficamente por Licenciandos em Educação do Campo em comunidades da região Norte do Estado de Minas Gerais. Seu principal objetivo é defender a integração dos conhecimentos tradicionais no Ensino de Ciências a fim de afirmar trocas interculturais. A partir da perspectiva teórica da Educação Intercultural e dos conhecimentos tradicionais dos povos do campo, crescente na Educação em Ciências, o presente estudo insere-se como resultado de ações de ensino, pesquisa e extensão. Ao longo dos últimos anos, um grupo de professores e estudantes tem identificado um conjunto de características que perpassam o modo próprio de pensar e falar de licenciandos, assim como de moradores de comunidades do campo, estreitamente relacionadas às suas práticas sociais. Tais conhecimentos emergem em disciplinas e pesquisas realizadas no contexto do Curso de Licenciatura em Educação do Campo de uma universidade federal. As informações obtidas ilustram a existência de nove das dez marcas apontadas. Os conhecimentos destacados demonstram ainda uma rica e coletiva produção cultural que não pressupõem um julgamento ou critério de verdade. Paralelamente, esses conhecimentos tradicionais e suas marcas/características constituem-se como uma contraposição importante para o Ensino de Ciências na medida em que almejam ser reconhecidos como uma cultura produzida, dotada de características próprias que muitas vezes se aproximam daquelas da cultura científica.

Palavras-chave: Conhecimentos tradicionais; Integração de saberes; Interculturalidade; Ensino de Ciências; Educação do Campo. 
The text presents, analyzes and discusses some of the marks/characteristics present in the traditional knowledge related to the influence of the Moon on the social practices of the rural people ethnographically mapped by undergraduate rural education in rural communities of the northern region of the state of Minas Gerais. Its main objective is to defend the integration of traditional knowledge in Science Teaching in order to affirm intercultural exchanges. From the theoretical perspective of Intercultural Education and the traditional knowledge of rural people, growing in Science Education, the present study is inserted as a result of the teaching, research and extension actions. Along the last years, a group of teachers and students have identified a set of characteristics that permeate the proper way of thinking and speaking of undergraduates and also of the residents of rural communities, closely related to their social practices. Such knowledge emerges in disciplines and research conducted in the context of the Undergraduate Course in Rural Education of a federal university. The results illustrate the existence of nine of the ten marks mentioned. The knowledge identified also demonstrates a rich and collective cultural production that does not presuppose a judgment or criterion of truth. At the same time, this traditional knowledge and its marks/characteristics constitute an important counterpoint to the teaching of sciences in that it aims to be recognized as a culture produced, endowed with its own characteristics that often approximate those of scientific culture.

Keywords: Traditional Knowledge; Integration of knowledge; Interculturality; Science Teaching; Rural Education.

\section{Introdução}

A dicotomia entre conhecimentos científicos e os ditos não científicos está posta desde o advento da ciência moderna. Tidos como inconciliáveis com os conhecimentos científicos, os demais sistemas de conhecimentos foram e continuam sendo silenciados por processos de colonização e negação das diferenças, que se utilizam do mito universalista da ciência ocidental de descrição e explicação da natureza. Comumente, esses outros conhecimentos são adjetivados como sendo primitivos, de senso comum, de estado bruto, irracionais, inferiores, ignorantes, impuros, atrasados, supersticiosos, dentre outras denominações pejorativas. O que não for científico, por assim dizer, está desprovido de razão e não possui validade ou tem reduzida legitimidade frente aos desafios colocados para a tomada de decisões na dita sociedade moderna, industrial, tecnológica e informacional em que estamos imersos.

Historicamente, a prática das ciências naturais e sociais reafirmou a incomensurabilidade entre esses sistemas de conhecimentos. Entretanto, mudanças nos campos da pesquisa antropológica, filosófica, sociológica e das etnociências têm contribuído para se pensar na integração, na complementariedade, em pontos de articulação e comparabilidade, e em momentos de intercâmbio e enriquecimento mútuo entre os diferentes conhecimentos (Argueta, 2015; El-Hani, 2018). 
Os diversos coletivos sociais, étnicos, raciais, de gênero, do campo, de povos e comunidades tradicionais, dentre outros que historicamente tiveram e ainda têm seu modo de viver expropriado e suas identidades silenciadas, são dinâmicos e ricos em diversidade, características que têm provocado incômodos, indagações que questionam a colonização de seus saberes e, do mesmo modo, interrogam a escola, a universidade e os próprios conteúdos curriculares das ciências que devem ser ensinados e praticados, nos conduzindo a um incessante (re)pensar pedagógico. Os diferentes sujeitos que chegam aos sistemas educacionais, sejam eles na educação básica ou superior, não estão mais dispostos a ter suas existências negadas pelo sistema de conhecimento imperante,

[...] demandam entrar nesses espaços do conhecimento legítimo, verdadeiro, não para sair do lado de lá, do não conhecimento, da ignorância, mas para por em diálogo horizontal a diversidade de conhecimentos. Ao afirmar-se sujeitos de conhecimentos, de culturas, ao defender seus territórios de existência, de trabalho, de lutas como lugares de culturas, de memórias, valores, conhecimentos, trazem para o campo do conhecimento a diversidade de experiências sociais de produção de conhecimentos. Trazem a diversidade de verdades em contraposição à dicotomia saber verdadeiro vs saber falso. Trazem a pluralidade de sujeitos de produção de conhecimentos em contraposição à dicotomia coletivos produtores e meros consumidores do saber verdadeiro, único (Arroyo, 2014, p. 217).

Diversas são as perspectivas e metodologias expressas em publicações na área da Educação em Ciências que propõem o tratamento dos chamados conhecimentos cotidianos, contextuais, primeiros (primevos), populares, tradicionais, dentre outras denominações que restituem a importância desses saberes para a ciência escolar e a vida cotidiana. De modo resumido, encontramos abordagens que se propõem a: contextualizar os conteúdos da ciência frente aos desafios da sociedade contemporânea e defender uma formação crítica e cidadã como é o caso da CTSA-Ciência, Tecnologia, Sociedade e Ambiente(Santos, \& Mortimer, 2000); resgatar a ciência dos saberes populares como modo de produzir novos saberes escolares, valorizando os conhecimentos locais e promovendo diálogos na comunidade (Chassot, 2016; Xavier, \& Flôr, 2015); desenvolver um perfil de concepções, no qual as novas ideias adquiridas no processo de ensino-aprendizagem passam a conviver com as ideias anteriores, reconhecendo a heterogeneidade dos modos de pensar e dizer e seus empregos situados epistêmica, histórica e socioculturalmente (Mortimer, 2001; Mortimer, Scott, Amaral, \& El-Hani, 2014); até, mais recentemente, defender a integração, intercultural, destes conhecimentos na formação de professores e no currículo escolar (Aikenhead, \& Michell, 2011; Crepalde, Klepka, \& Halley, 2017; Kanu, 2011).

A Educação Intercultural tem colaborado para a promoção da inter-relação entre diferentes grupos culturais, não assumindo a homogeneização ou assimilação cultural ou a diferenciação essencializadora de culturas, mas sim concebendo as culturas como num processo contínuo de construção e reconstrução, no qual o híbrido cultural é antes a regra do que a exceção. Além disso, assume que as relações culturais estão atravessadas por 
questões de poder, por relações fortemente hierarquizadas, marcadas pelo preconceito e pela discriminação de determinados grupos. A Educação Intercultural caminha para a negociação cultural, defendendo a articulação de políticas de igualdade com políticas de identidade, favorecendo a integração dialética das diferenças para combater os conflitos provocados pela assimetria de poder entre os diferentes grupos socioculturais (Candau, 2008).

Nosso alinhamento à perspectiva intercultural no Ensino de Ciências na Educação do Campo se deve à busca pelo rompimento com a assimetria imposta pela hegemonia das ciências modernas em que as explicações válidas são apenas as testadas e comprovadas pela ciência ocidental (Crepalde, \& Aguiar Jr., 2014; El-Hani, 2018). Acreditamos que defender a interculturalidade no Ensino de Ciências implica: reconhecer os privilégios do discurso científico ou de quem o enuncia; criar deslocamentos e estranhamentos que descentrem visões baseadas em um realismo ingênuo; promover efetivamente a troca intercultural visando o enriquecimento mútuo de perspectivas; e, assumir a possibilidade de complementaridades e cooperação de formas distintas de conhecimento frente a desafios concretos da vida cotidiana.

Defendemos a ideia da integração dos saberes tradicionais oriundos dos contextos campesinos à formação de professores de ciências para o campo. Partimos do entendimento de que os conhecimentos tradicionais provenientes e/ou estreitamente relacionados às práticas sociais do campo presentes nas comunidades de origem de licenciandos do campo e emergentes na sala de aula constituem-se de sistemas de conhecimentos legítimos desses povos, de sua história de luta pela terra e pela sobrevivência, de memórias individuais e coletivas.

Neste texto apresentamos um conjunto de marcas/características presentes nos conhecimentos tradicionais diretamente relacionados às práticas sociais dos povos do campo. Para isso são analisados dados provenientes de um mapeamento de cunho etnográfico realizado por Licenciandos em Educação do Campo acerca dos conhecimentos tradicionais relacionados à Lua praticados em comunidades da região Norte do Estado de Minas Gerais.

O trabalho apresenta-se, desse modo, simultaneamente teórico e empírico, pois, se de um lado busca fundamentar o que entendemos por conhecimentos tradicionais, por outro atua como um exercício demonstrativo que ressalta nossa tese sobre a existência de marcas/características emergentes dos conhecimentos tradicionais e a possibilidade de sua integração no Ensino de Ciências promovendo verdadeiros diálogos interculturais.

\section{Os conhecimentos tradicionais}

Chamamos de conhecimento tradicional o discurso associado às práticas sociais, que têm sua gênese na tradição e luta populares, comumente transmitido pela oralidade e, predominantemente, organizado pelo modo narrativo. Trata-se de discurso que se opõe como resistência (epistemológica) aos processos de colonização tal como a ideologia da modernização conservadora propagada pelo agronegócio (Alentejano, 
2003; Silva, 2015).

Há, portanto, uma relação indissociável entre os discursos ou conhecimentos que adjetivamos como tradicionais e as práticas sociais desenvolvidas em comunidades, no nosso caso, as do campo. Cabe reafirmar a dimensão social dessas práticas uma vez que sua recorrência não se dá de modo arbitrário, neutro e isolado. Pelo contrário, práticas sociais são ideológicas, têm sua história, estão envolvidas em relações de poder e fazem parte do mundo simbólico e cultural das suas comunidades de origem. Ou seja, a prática social de plantio e colheita de mandioca, por exemplo, não se explica sozinha, tampouco pelos agricultores que desenvolvem essa atividade, mas sim, só podemos compreender a mandioca no contexto do semiárido mineiro de luta pela terra e por água, da agricultura familiar e da afirmação dos direitos dos povos do campo.

No Brasil, há uma grande variedade de comunidades unidas pela tradição e lutas populares. São exemplos de populações tradicionais: quilombolas, catingueiros, raizeiros, geraizeiros, veredeiros, ribeirinhos, faxinalenses, entre outros, que desempenham atividades agrícolas, pastoris, artesanais, de caça, extrativismo, etc. (Argueta, 2015; Coordenadoria de Inclusão e Mobilização Sociais [CIMOS] \& Ministério Público de Minas Gerais [MPMG], 2018).

Denominarcertodiscursodetradicionaltambém carrega algumasdificuldades.Em primeiro lugar, temos consciência de que há todo um acúmulo de debates e controvérsias acerca dos direitos intelectuais de determinados conhecimentos tradicionais, inclusive com legislação nacional e acordos internacionais sobre o tema (Carneiro da Cunha, \& Almeida, 2009). Mas no nosso caso, tratamos o conhecimento tradicional mais como adjetivo do que como substantivo. Ou seja, estamos mais preocupados em caracterizar e discutir o conhecimento no que se refere às diferenças, contrastes e comparações do que abordar sua autoria, mecanismos de compartilhamento e implicações legais fora da comunidade. Em segundo lugar, diferentemente do conhecimento científico que contou com processos de unificação, generalização e universalização para sua justificação ideológica, o conhecimento tradicional, ou melhor, os conhecimentos tradicionais são múltiplos, tão diversos quanto são as comunidades que os (re)produzem: "há pelo menos tantos regimes de conhecimento tradicional quanto existem povos" (Cunha, 2009, p. 302).

\section{A integração dos conhecimentos tradicionais e científicos}

A perspectiva de integração dos conhecimentos tradicionais e científicos tem sua gênese na Educação em Ciências com a obra "Educação científica para todos" (2009). Nela, Glen S. Aikenhead, filho e neto de agricultores, inicia a discussão acerca da importância do cruzamento de fronteiras culturais na sala de aula de ciências onde a subcultura da ciência é apenas mais uma das possibilidades de se transitar diante das inúmeras culturas existentes no ambiente escolar. De lá para cá o autor tem caminhado do diálogo intercultural entre as subculturas da ciência e do contexto de cada aluno, para a efetiva integração das formas indígenas (aborígenes) de compreender a natureza na formação de professores e no currículo de ciências. 
O contexto de seus últimos trabalhos, produzidos em colaboração com professores de diferentes etnias como Herman Michell, aborígene de descendência Cree, resulta de um movimento internacional pós-colonial que reivindica os direitos e soberania dos povos indígenas. O Canadá, país no qual os autores desenvolvem suas pesquisas e proposições curriculares interculturais, já conta com uma série de políticas públicas com o propósito da reconciliação com os povos aborígenes em função das violências simbólicas e materiais provenientes dos processos de colonização que têm seus desdobramentos até os dias atuais.

Ao proporem aos professores de ciências a construção de pontes culturais (bridging cultures) entre as formas científica e indígena de se conhecer a natureza, esses autores defendem que para além do reconhecimento dos contextos de uso desses modos distintos de experimentar e explicar o mundo, os conhecimentos indígenas, e, no nosso caso, estendemos aos conhecimentos tradicionais, podem ser objetos da ciência escolar. Se, de um lado, o Ensino de Ciências teria que ampliar e/ou modificar suas metas de ensino e aprendizagem ao reconhecer os conhecimentos tradicionais como merecedores do tratamento em sala de aula para promover a visibilidade e fortalecimento de identidades de povos e comunidades tradicionais; de outro lado, para os demais educandos em ciências que não compartilhassem dessas culturas (brancos, não-indígenas, urbanos etc. ou aqueles em que o mundo da ciência confunde-se com sua própria vida) teriam a oportunidade de entrar em contato com outras epistemologias que não a ocidental. Tal cruzamento de fronteiras significaria uma ampliação de seus repertórios de entendimento da natureza e da sociedade. Portanto, a integração dos conhecimentos tradicionais nas aulas de ciências contribuiria também para o desenvolvimento da cidadania, da tolerância e do respeito à alteridade.

Isso não quer dizer que negamos a importância dos conhecimentos científicos ou que o letramento científico deveria deixar de fazer parte dos propósitos do Ensino de Ciências: o conteúdo científico convencional continuará a ser ensinado, mas não será apresentado como a única maneira de entender a natureza (Aikenhead, \& Michell, 2011). Tampouco queremos dizer que qualquer conhecimento deva ser integrado. Nesse sentido, há, pelo menos, três posições que emergem dessa discussão e merecem ser consideradas:

i) Há algum conhecimento que não mereça ser reconhecido e, inclusive, ser objeto de desconstrução nas aulas de ciências? Sim, todos aqueles que firam a dignidade humana $^{1}$ e sejam instrumento da perpetuação de desigualdades.

ii) Há conhecimentos que devem ser reconhecidos e não integrados? Sim, a própria abordagem dos perfis conceituais já aponta o reconhecimento e destaca o ensino dos conceitos científicos como meta da ciência escolar. Evidentemente a decisão

1 É claro que a ideia de direitos humanos ou dignidade humana também merece ser relativizada culturalmente e objeto de desconstrução. No entanto, como afirma Candau (2008, p. 48): “Todas as culturas possuem concepções da dignidade humana. Nem todos os grupos culturais conhecem ou usam a expressão direitos humanos, mas isso não quer dizer que não tenham uma ideia de dignidade humana, de vida digna, de querer uma vida melhor para os seus habitantes ou para seus integrantes. Temos de ter sensibilidade para descobrir em cada universo sociocultural essa ideia de dignidade humana que traduzimos como direitos humanos". 
de não integração de determinados conhecimentos é política, pedagógica e curricular e insere-se em um terreno de disputas.

iii) Quais conhecimentos devem ser reconhecidos e integrados? É difícil afirmar categoricamente, pois também nesse caso trata-se de uma decisão. Mas, do nosso ponto de vista, aqueles conhecimentos relacionados às práticas sociais desenvolvidas pelos educandos e/ou suas comunidades que favoreçam mutuamente o desenvolvimento de conceitos científicos. No nosso contexto, da formação de professores de ciências para o campo, podemos elencar temas passíveis dessa integração: sementes crioulas, biofertilizantes, repelentes naturais, relação das plantas com as culturas e sociedade, segurança alimentar, práticas de cuidado, uso do solo, artefatos tecnológicos do campo, dentre outros que relacionam-se às identidades ligadas à vida no/do campo.

Mais do que idealmente assumir a possibilidade da integração dos conhecimentos, de enunciar a importância do diálogo intercultural de saberes ou hastear uma bandeira de uma nova utopia para a Educação em Ciências, pretendemos, a partir de agora, expor algumas concretizações, resultados de pesquisas e reflexões sobre a prática pedagógica que estamos imersos no contexto da formação inicial e continuada de professores de ciências para o campo.

Ao longo dos dois últimos anos temos identificado, por meio das práticas sociais dos povos do campo, um conjunto de características que perpassam o modo próprio de pensar e falar de licenciandos e também dos moradores de suas comunidades, emergentes nas disciplinas e pesquisas realizadas no contexto do Curso de Licenciatura em Educação do Campo de uma universidade federal. No grupo de estudos e pesquisas do qual os autores participam e desenvolvem suas ações, temos tido a oportunidade de construir relações na condição de outsiders seja em projetos extensão, iniciação científica ou mesmo nos momentos da alternância ${ }^{2}$ nos quais realizamos visitas orientadas por propósitos de ensino.

As características desses discursos, que denominamos de tradicional, ou do conjunto de discursos tradicionais que emergem dos sujeitos do campo nas situações mencionadas anteriormente, em diálogo com contribuições, em especial, de perspectivas interculturais, de reflexões antropológicas e, mais recentemente, via leituras e reflexões a partir do trabalho de Aikenhead e Michell (2011), Bridging Cultures, nos inspiraram a transpor em alguns casos, dando nosso próprio tom, e a construir em outros, uma série de marcas distintivas destes conhecimentos.

Antes de passarmos à exposição mais sistematizada dessas marcas/características dos conhecimentos tradicionais, é importante destacar que esses discursos fazem parte de um sistema racional de conhecimento como qualquer outro, uma vez que possui

2 A Pedagogia da Alternância é uma metodologia que busca a interação entre o estudante que vive no campo e a realidade que ele vivencia em seu cotidiano, de forma a promover constante troca de conhecimentos entre seu ambiente de vida e trabalho e a universidade. É uma proposição de organização dos tempos formativos, na qual se alternam tempos de estudo/reflexão/pesquisa intensivos na escola/universidade e tempos de estudo/reflexão/ pesquisa junto às comunidades de origem dos educandos, foi adotada pela primeira vez pelas escolas família agrícolas. 
uma epistemologia própria, mas, principalmente, porque como qualquer tipo de conhecimento, os conhecimentos tradicionais compõem-se de um conjunto dinâmico de artefatos que medeiam as ações humanas e são produzidas por eles para atuar em determinados contextos (Aikenhead, \& Michell, 2011). Além dessa propriedade inerente, os conhecimentos tradicionais presentes em práticas sociais do campo podem ser demarcados a partir de dez marcas/caracterizações como as que apresentamos na Figura 1.

\begin{tabular}{|c|c|}
\hline \multicolumn{2}{|c|}{ Conhecimentos Tradicionais } \\
\hline Local & $\begin{array}{l}\text { Fortemente demarcado pela relação entre a identidade e o espaço (território, } \\
\text { terra como identidade) de pertencimento do sujeito. Assume uma relação mais } \\
\text { profunda com o espaço, dependente do contexto, restrita, não generalizável. }\end{array}$ \\
\hline Monista & $\begin{array}{l}\text { Considera a realidade (espiritual e física) como um todo. Não assume dualismos } \\
\text { tais como: mente x corpo, sujeito x objeto, natureza x cultura, material x não- } \\
\text { material. }\end{array}$ \\
\hline Holístico & $\begin{array}{l}\text { As partes mantêm inter-relações com o todo e não podem ser isoladas. Também } \\
\text { se refere a um equilíbrio/harmonia dos aspectos mental, espiritual, emocional e } \\
\text { físico do ser. Todas as partes da vida estão inter-relacionadas. }\end{array}$ \\
\hline $\begin{array}{l}\text { Relacional } \\
\text { responsivo }\end{array}$ & $\begin{array}{l}\text { O mundo das relações é responsivo e exige o exercício da alteridade. Na medida } \\
\text { em que experimentamos o mundo também somos vivenciados por ele. É um ato } \\
\text { recíproco. }\end{array}$ \\
\hline (Des)conhecido & $\begin{array}{l}\text { Constante fluxo na natureza que produz realidades compreensíveis e } \\
\text { incompreensíveis. Não há a expectativa de compreensão de "tudo". Exercício } \\
\text { da humildade. }\end{array}$ \\
\hline Validade & $\begin{array}{l}\text { Validade baseada no conteúdo, seu contexto, e não na sua capacidade preditiva. } \\
\text { Se usam-existe-vive hoje, então é válido. Admite explicações divergentes. } \\
\text { Conhecimento da natureza como ela é e não como ela funciona. }\end{array}$ \\
\hline Dinâmico & $\begin{array}{l}\text { Transformado de geração em geração, sempre contemporâneo. Não é uma } \\
\text { repetição, as informações são experimentadas, comparadas e produzidas à } \\
\text { "luz" de cada geração. }\end{array}$ \\
\hline $\begin{array}{l}\text { Sistematicamente } \\
\text { empírico }\end{array}$ & Profunda observação e experimentação do mundo natural. \\
\hline Temporalidade & $\begin{array}{l}\text { Distintas temporalidades convivem harmonicamente: indissociáveis do sujeito; } \\
\text { tempos cíclicos (não há início e fim). }\end{array}$ \\
\hline Espiritualidade & $\begin{array}{l}\text { Fluxo permanente de "algo" que perpassa os sujeitos, os fenômenos físicos e } \\
\text { não físicos e tende a buscar equilíbrio e harmonia na existência. Diferente de } \\
\text { religião ou paradigma concorrente ao da ciência. }\end{array}$ \\
\hline
\end{tabular}

Figura 1. Marcas/características dos conhecimentos tradicionais 
Nas próximas seções exploramos em maiores detalhes essas marcas/ características discursivas a partir de enunciados emitidos por moradores do campo quando interrogados sobre a possível relação entre as fases lunares e práticas sociais desenvolvidas por eles.

\section{Contextos de produção}

Para as comunidades do campo localizadas na região Norte de Minas Gerais, a natureza, a terra, a água, a vegetação e a biodiversidade são muito mais do que a base da sua sobrevivência, constituem sua existência, seu viver, suas identidades (Brito, 2012). Encontramos, neste local, laços comunitários profundos, frutos da resistência e da reafirmação de um modo de vida alternativo às pressões da monocultura do eucalipto, da mineração, do carvoejamento, do latifúndio, enfim, da modernização conservadora empreendida pelo agronegócio sob a ideologia do desenvolvimento e progresso para todos.

Quando se fala em modernizar o Cerrado, as populações da região tampouco são consideradas. Modernizar é, mais uma vez, sinônimo de colonizar o Cerrado, negando a existência desses povos, que se desenvolveram com a natureza, e não contra a natureza. Esses povos hoje têm um patrimônio de conhecimento que interessa à humanidade como um todo. Onde hoje estão as regiões mais ricas em diversidade biológica do planeta? São aquelas que não passaram pelo processo de modernização. (PortoGonçalves, 2014, pp. 166-167).

A identidade comunitária no Norte de Minas Gerais carrega ainda a noção compartilhada de comunidade que, segundo Brito (2012), é resultado de um hibridismo entre a fazenda originária em termos da sua localização geográfica e a comunidade religiosa. A partir de meados da década de 1970 têm-se o surgimento das CEB`s (Comunidades Eclesiais de Base) na região, o que reconfigurou as relações comunitárias para além do parentesco, amizade ou trabalho, novas demarcações do espaço foram criadas pelos laços de fé, reflexão e solidariedade junto com o compromisso de transformar a realidade (Nogueira, 2009).

Não por ser patrimonialmente uma guardiã do passado, ou por ser expressivamente "folclórica", "típica" ou um "genuíno exemplo de nossas mais preciosas tradições", uma comunidade popular (mas nem todas elas) é também tradicional. Ela o é por representar uma força ativa e presente de resistência à quebra de um reduto inter-humano de relações ainda centradas mais em pessoas e rede de reciprocidade de/entre sujeitosatores através de produto do trabalho, do que em coisas e trocas de mercadorias através de pessoas, tornadas elas próprias, seres-objeto. (Brandão, 2012, p. 373).

Uma das populações tradicionais desse território são os Geraizeiros.

Geraizeiros são chamados os camponeses da porção de Cerrado no Norte de Minas Gerais - bem como noutras localidades, sobre as quais se estendem os Gerais, destacadamente o Noroeste do estado de Minas e o Oeste da Bahia, onde a alcunha ainda é corriqueiramente utilizada. Gerais, grosso modo, pode ser aqui entendido como sinônimo de Cerrado, paisagem que, no Norte de Minas Gerais, teve grande parte de sua extensão convertida 
em maciços de eucalipto, desde a década de 70. O plantio empresarial de eucalipto implicou em expropriação, grilagem de terras comunais e grande impacto ambiental, com a redução da oferta de água, frutos nativos, ervas medicinais e madeira - recursos estratégicos para reprodução física e social dos Geraizeiros. (Nogueira, 2009, p. 15).

De modo geral, os Geraizeiros possuem produção agrícola para alimento próprio e com a venda do excedente na feira da cidade; criação de animais de pequeno porte; extrativismo dos frutos do cerrado (pequi, araticum, mangaba, maracujá do mato, dentre outros). Cabe destaque a centralidade do cultivo da mandioca e do preparo de seus derivados (goma, farinha, bolos, etc.). No entanto, segundo Carrara (2007), em consequência da degradação do Cerrado e, com isso, o enfraquecimento das estratégias tradicionais de segurança alimentar, grande parte das famílias tornou-se dependente de auxílios tais como Bolsa Família, cestas básicas, aposentadorias e também da realização de trabalhos sazonais, para os quais, por vezes, migram temporariamente para outras regiões.

Neste contexto, os dados analisados a seguir são resultados do trabalho de pesquisa de licenciandos do campo do curso de Licenciatura em Educação do Campo de uma universidade federal, sob orientação de uma equipe de professores, com a intenção de construir um mapeamento de cunho etnográfico dos conhecimentos tradicionais relacionados à Lua de comunidades do campo em que os próprios estudantes convivem: Rio Pardo de Minas ${ }^{3}$, na região Norte do Estado de Minas Gerais.

Inicialmente, a temática da Lua emergiu de uma proposta de trabalho final da disciplina Introdução à Física do curso mencionado que tinha como objetivo a pesquisa sobre o modo como os conhecimentos científico e tradicional estão relacionados à Lua e as suas implicações para o ensino de ciências. Naquele momento, notamos que sob a ótica do conhecimento científico, as produções escritas dos estudantes aproximavam-se do discurso citado (aquele dito pelos livros acadêmicos ou didáticos) e mantinham pouca ou nenhuma relação com o cotidiano deles. No entanto, quando se pronunciavam em relação às práticas sociais desenvolvidas por suas famílias e comunidades que tomavam como orientação as fases lunares, o texto produzido carregava fortes marcas de autoria, demonstrando que outros conhecimentos, os tradicionais, estavam entrelaçados em suas vidas no/do campo. Esta reflexão, por assim dizer, de ensino, converteu-se, em seguida, em propostas de pesquisas por meio de iniciações científicas e trabalhos de conclusão de curso. Mais recentemente, como um retorno ao ensino, foi construída uma regência de estágio supervisionado obrigatório a partir desta temática, fundamentada nos resultados de pesquisa obtidos.

Dito isso, o mapeamento realizado pelos estudantes da Licenciatura em Educação do Campo foi tratado sob dois pontos de vista que nos esforçamos por manter

3 Rio Pardo de Minas possui uma população de aproximadamente 29 mil habitantes (Instituto Brasileiro de Geografia e Estatística [IBGE], 2018). O município está situado na microrregião de Salinas (MG), região de alta biodiversidade, com fauna e flora típica de paisagens do Cerrado em transição com a Caatinga possuindo uma enorme riqueza cultural no que tange suas populações no convívio com o território. 
em permanente diálogo ao longo de todo trabalho de pesquisa: i) o dos professores orientadores, mais experientes academicamente e com acúmulo teórico e metodológico na temática, objeto de pesquisa, porém outsiders em relação à comunidade; ii) o dos graduandos bolsistas e voluntários de iniciação científica, em processo de formação inicial acadêmica, mas insiders com possibilidades de acesso a zonas mais profundas de significação da comunidade e de compreensão do seu modo de vida.

O trabalho de campo consistiu em visitas às famílias das comunidades do campo investigadas; realização de entrevistas semiestruturadas com o tema da Lua (Figura 2) e sua influência nas atividades do dia a dia, com gravação em áudio e posterior transcrição; registro em caderno de campo das observações dos aspectos não-verbais das interações e do contexto de produção das entrevistas, apontamento das dificuldades, possíveis contradições e possibilidades para coleta de mais informações por outros instrumentos ou até mesmo a busca de novos sujeitos para serem entrevistados ${ }^{4}$.

\section{ROTEIRO DE ENTREVISTA SEMIESTRUTURADA}

Objetivo de Pesquisa: Construir mapeamento de cunho etnográfico dos conhecimentos tradicionais relacionados à Lua que orientam práticas sociais de comunidades do campo localizadas na região Norte do estado de Minas Gerais

1. Há quanto tempo você reside e/ou trabalha nesta comunidade?

2. Quais são suas atividades aqui na comunidade?

3. Quais plantas você tem cultivado e para quê?

4. Que animais são criados e para quê?

5. Quais conhecimentos (técnicas, procedimentos ou orientações) que você utiliza na plantação e na criação de animais que foram repassados a você por seus pais, avós, familiares ou conhecidos da comunidade?

6. Há algum desses conhecimentos que utiliza a Lua como orientação?

7. Como você explica essa influência?

8. Tem alguém que você conhece que usa essa influência de forma diferente?

9. Você sabe explicar o porquê dessa diferença?

10. Você acredita que esses conhecimentos estão fortes na sua comunidade ou estão se perdendo com as gerações? Quais seriam os motivos?

11. Como você vê a importância desses conhecimentos/saberes para a comunidade?

12. Como você acredita que a escola poderia contribuir para a valorização desses conhecimentos?

Figura 2. Roteiro de entrevista semiestruturada

4 Pesquisa aprovada pelo Comitê de Ética CAAE 65815817.2.0000.5154. 
Os sujeitos-entrevistados, moradores de comunidades do campo, desenvolvem práticas de cultivo e criação de animais, seja para consumo próprio ou para venda, com destaque especial para o plantio de mandioca e a produção de seus derivados (farinha, goma/fécula). Eles são reconhecidos em suas comunidades como pessoas de referência, lideranças, pelo seu envolvimento com as causas e demandas locais, a exemplo da associação de moradores ou em ações do sindicato dos trabalhadores rurais do município e, é claro, pela experiência adquirida, ao longo dos anos, no trabalho na/da terra.

$\mathrm{Na}$ análise destes dados, optamos pelo emprego da palavra conhecimento ao invés de saber por entender que o primeiro é mais restrito e contextual tal como discurso, assumido por nós em uma perspectiva bakhtiniana: "[...] o discurso, ou seja, a língua em sua integridade concreta e viva, e não a língua como objeto específico da linguística, obtido por meio de uma abstração absolutamente legítima e necessária de alguns aspectos da vida concreta do discurso" (Bakhtin, 2010, p. 181). Nesse sentido, o discurso é formado por diversas vozes (posições sociais, pontos de vista); responde a outros dizeres; possui uma história; manifesta-se como enunciados concretos de determinados falantes. Em outras palavras, o discurso é constitutivamente dialógico, ideológico e histórico (Flores, Barbisan, Finatto, \& Teixeira, 2009).

De outro modo, o saber, ou melhor, os saberes, diferem dos conhecimentos por neles estarem incluídos, sendo, por isso, determinados e determinantes de identidades. Isso não quer dizer que não levamos em conta os saberes e as identidades, mas sim os pressupomos. Assim, na análise que nos propomos a fazer de interações verbais com e a partir de sujeitos do campo, nosso olhar volta-se prioritariamente ao discurso na sua acepção mencionada anteriormente.

\section{Interpretação}

As informações analisadas correspondem a um pequeno recorte do conjunto total de dados que compõem o mapeamento realizado sobre as práticas sociais do campo orientadas pelas fases lunares. Cabe ressaltar que a intenção com essa breve análise não foi debruçar-se sobre todos os enunciados emitidos e com isso tentar esgotar seus sentidos. Ao invés disto, ela antes teve o propósito de tornar compreensível o conjunto de marcas/ características dos conhecimentos tradicionais que desenvolvemos teoricamente em seções anteriores. Assim, na exposição das informações obtidas e de sua interpretação, optamos por privilegiar trechos dos discursos dos sujeitos pesquisados que demonstram de forma mais nítida as características dos conhecimentos tradicionais do que organizar o texto em função de cada entrevistado isoladamente ou de alguma atividade em especial. Destaca-se ainda que os sujeitos pesquisados tiveram suas identidades preservadas, por isso, seus enunciados são retratados por intermédio de nomes fictícios.

Nossa primeira análise dos moradores do campo residentes em comunidades de Rio Pardo de Minas-MG inicia-se com a entrevista do senhor Manuel de 45 anos de idade, morador da comunidade Barra do Córrego há 25 anos. A comunidade é pequena, possui cerca de 20 famílias, sendo todos lavradores. Grande parte das casas está localizada 
perto do rio que fornece água às famílias, daí a origem de seu nome: Barra do Córrego.

O senhor Manuel trabalha como diarista em uma fazenda vizinha da sua comunidade, onde exerce a função de zelador, atuando também no manejo de animais como gado e galinhas, das lavouras e do pomar de frutas, principalmente o de banana e mexerica poncã que são os mais cultivados. No decorrer da conversa, o aluno pesquisador questionou ao senhor Manuel se, nessas plantações que faz, já havia notado diferença com plantações de outras lavouras que não foram plantadas na Lua certa:

Já... teve uma vez assim... quando mudei pra cá, plantei uma manaíba lagoinha [tipo de mandioca utilizada para produção de goma]. Nem era muito boa, mas na Lua certa deu cada raiz! Aí no outro ano plantei da mesma. Mas no forte... deu raiz tudo pequena... uma terra só. Por causa da Lua. Povo falava que era mentira, mas depois disso eu acredito, porque já tirei o teste (senhor Manuel).

De início notamos que é significativa a orientação pelas fases lunares nas práticas desenvolvidas pelo senhor Manuel. A influência da Lua sobre as plantações não é determinada em si pelo dia exato que corresponde às quatro fases da Lua: nova, quarto crescente, cheia e quarto minguante. É como se existissem basicamente dois períodos: um no qual a Lua cresce, do dia em que inicia ou um dia após a Lua Nova, passando pelo quarto crescente até o dia de Lua Cheia (Lua forte); e outro no qual a Lua mingua, do dia em que inicia ou um dia após a Lua Cheia, passando pelo quarto minguante, até a Lua Nova (Lua fraca). Dito isso, outro ponto que percebemos na fala do senhor Manuel é a estreita relação com a comunidade, explicitamente com a terra na qual vive e produz, caracterizada pelos plantios consecutivos em "uma terra só", independente da qualidade de mandioca, que segundo ele, "nem era muito boa".

Esta relação fortemente demarcada dos sujeitos com a terra, entendendo aqui terra como território de pertença, acrescenta ao conhecimento tradicional a característica de ser local e, portanto, não generalizável ou universal. Relação esta constituída nas experiências e vivências de cada contexto, de cada sujeito do campo, desenvolvidas em suas interações com o meio ambiente, os cultivos, criações, noções de sazonalidade, ciclos naturais, etc. Fruto da observação da dinâmica local aliada à sua vivência desempenha importante papel na formação da(s) identidade(s) desses povos, por isso, está(ão) fortemente demarcada(s) pela questão identitária. "O conhecimento baseado no local e incorporado na identidade cultural de alguém vai com a pessoa onde quer que ela viva, inclusive em uma grande cidade" (Aikenhead, \& Michell, 2011, p. 74, tradução nossa).

Ao mesmo tempo, a fala do senhor Manuel apresenta a dinamicidade (dinâmico) do conhecimento tradicional, as tentativas de plantio e os diferentes resultados obtidos. Ao ser transformado de geração em geração, o conhecimento tradicional é sempre contemporâneo. Não é uma mera repetição. As informações são experimentadas, comparadas e produzidas à "luz" de cada geração e incorporadas nas observações das gerações subsequentes.

Também pode ser destacada neste pequeno trecho da entrevista com o morador 
de Barra do Córrego a empiria sistemática (sistematicamente empírico), retratada pelo seu próprio discurso "no outro ano plantei da mesma", e, "eu acredito porque já tirei o teste" paralelamente às marcas de validade e temporalidade. Nesse sentido, é possível perceber que os conhecimentos dos povos do campo nascem da profunda e sistemática observação e experimentação do mundo natural. A observação é o ponto de partida para a construção de conhecimento, seguida de experiências sistemáticas e posterior compartilhamento colaborativo na comunidade, analisada e comparada com a observação efetuada por todos, mesmo que o "Povo falava que era mentira".

Essa observação e previsão, ratificada ou modificada ao longo dos anos, faz dos camponeses especialistas em suas atividades de criação de animais, plantação, produção e uso do solo. Se este conhecimento do senhor Manuel ainda sobrevive no tempo após 25 anos, então ele é válido (validade). A validade do conhecimento também está fortemente atrelada à questão de sua localidade, ou seja, seus contextos de produção. $\mathrm{O}$ conhecimento válido para uma determinada região (territorialidade) pode não servir a todas as demais.

As formas de conhecimento [...] são produtos de uma experiência humana válida em um ambiente relativamente semelhante desenvolvido durante um longo período de tempo; e por esse motivo, é válido em si mesmo. A validade tem a ver com o fato de que as pessoas [...] ainda estão aqui hoje. Nós sobrevivemos usando nossos próprios sistemas de conhecimento (Michell, Vizina, Augustus, \& Sawyer, 2008, p. 76 citado em Aikenhead, \& Michell, 2011, p. 88, tradução nossa).

Dentre esses próprios sistemas de conhecimento, a noção de temporalidade pode ser destacada no discurso e principalmente na prática do agricultor. Característica do conhecimento tradicional dos povos do campo, as distintas temporalidades reconhecem não apenas o passado, presente e futuro fundamentais para as ciências eurocêntricas. Comporta assim uma relação não linear de tempo, antes cíclica. A temporalidade que atribuímos ao conhecimento tradicional do senhor Manuel permite uma relação com o tempo que admite a noção de passagem de tempo como o espaço entre eventos, os plantios, conferindo ao tempo a característica cíclica. São temporalidades importantes para a compreensão da natureza e observadas a cada geração os padrões e ritmos dos fenômenos como, no exemplo aqui destacado, o plantio sob a influência das distintas fases da Lua. Portanto, o que ocorreu ontem ou há anos não é passado, findado, se ele continua a se repetir. Assim, o tempo pode ser considerado no saber dos camponeses como um fenômeno cíclico.

Na sequência apresentamos trechos de três entrevistas que dialogam com a mesma lógica, embora de sujeitos de comunidades do campo distintas. Nestas entrevistas, realizadas individualmente, os pesquisadores questionam sobre a existência de práticas de plantio segundo determinadas fases da Lua tanto pelo entrevistado quanto em relação à sua comunidade. Observemos suas respostas a estes questionamentos:

Os mais velhos mesmo perdiam o molhado pra guardar a Lua. Já hoje você não usa mais isso porque, se perdeu a primeira chuva, seja Lua forte ou Lua minguante, tem que 
aplicar a semente na hora. Veio a chuva, aplica a semente. E agora se der certo, se chove e a Lua tiver minguante, nós planta. Porque, vai que até esperar o chão não vai tá mais molhado, e se plantar antes, ela vai desenvolvendo (senhor José).

Tem. A Lua comanda tudo, né?! Tem gente que fala ah... Lua manda em nada não. Aqui já aconteceu de já está com a terra prontinha aí vem chuva, ainda nós espera. A mulher fala: Ah... tem que planta logo, aproveita o molhado, não sei o que. Mas tem hora que a gente passa 8, 9 até 10 dias esperando chegar o dia certo de plantar para plantar sempre na Lua certa né?! (senhor Nivaldo).

Quase todo mundo aqui planta na Lua. Aqui, muita gente aqui, choveu hoje a terra tá molhada, ou, a Lua não tá boa, não vou plantar não e espera a Lua. E, acabando essa espera da Lua com a pouca chuva acaba o produtor perdendo a safra, porque vai esperar a Lua, tá seco e mantimento não vai nascer. Tem muitos que não tem negócio de Lua (senhor Aparecido).

No primeiro trecho, o entrevistado é senhor José de 61 anos, morador da comunidade Tatu, que conta com mais de 52 famílias residentes ao longo do Rio Preto que liga as comunidades Barra do Córrego e Duas Veredas. O senhor José sempre morou nessa comunidade com a esposa, trabalha principalmente em sua serraria onde faz bonecos (cilindro de madeira acoplado às lâminas de serra) usados para ralar mandioca na produção de farinha e goma. Seus principais afazeres como agricultor consistem no plantio da mandioca para feitura e venda da farinha e da goma e no cultivo de milho.

Senhor Nivaldo tem 65 anos de idade e é nascido e criado na comunidade Santa Maria localizada ao longo de um rio. Em épocas passadas, teve muitas baixas no cultivo de arroz, por causa das enchentes no local. Atualmente, Nivaldo reside na comunidade Ribeirão. Já são 41 anos nesta terra que possui apenas cerca de 15 famílias que construíram suas casas ao longo de uma vereda. Nivaldo, que já foi tratorista, desenvolveu muitas atividades durante sua vida na criação de gado e plantio de mandioca, cana-de-açúcar, milho e outros cultivos. No entanto, assim que se mudou para a comunidade Ribeirão, atuou tocando tropas de burros em viagens às caatingas nas regiões de Mato Verde e Porteirinha (MG). Era também por meio dessas viagens que senhor Nivaldo conseguia obter lucro com a venda de seus produtos como farinha, goma, feijão, café e cachaça.

Por fim, senhor Aparecido, morador da comunidade Baixa Grande que conta com 48 famílias e é distante $30 \mathrm{~km}$ da sede do município. Aparecido é camponês da região reconhecido pelo emprego e compartilhamento de conhecimentos tradicionais no campo. Ele tem 65 anos, sempre morou e trabalhou no campo, é estudioso de plantas medicinais e produz alguns remédios caseiros que, inclusive, são vendidos em uma pequena loja de produtos naturais no prédio do Sindicato dos Trabalhadores Rurais de Rio Pardo de Minas. Além disso, participa de eventos relacionados à agricultura familiar e à adubação alternativa com o propósito de incentivar sua comunidade e aquelas vizinhas da importância da produção livre de agrotóxicos.

O que nos chama a atenção nos discursos dos três moradores do campo 
destacados é a relação temporal, dinâmica, relacional e responsiva atribuída ao plantio. Esta relação é menos presente na prática atual do senhor José, possivelmente devido aos processos de escassez de água sofridos por muitas comunidades de Rio Pardo de Minas devido à monocultura do eucalipto, mas ainda guarda em sua memória um modelo de validade local "Porque, vai que até esperar o chão não vai tá mais molhado". Portanto, a existência, a sobrevivência de sua família é dependente de uma rede de inter-relações sustentadas por responsabilidades, relacionamentos responsivos entre as coisas e as pessoas (relacional e responsiva). Ao associarmos a fala de senhor José ao contexto de suas práticas produtivas percebemos que a dependência do comércio é muito forte para sua subsistência. Isso resulta que, embora a Lua seja importante, o tempo das águas é o que permitirá a manutenção de sua existência bem como de seus familiares. Isso gera uma rede de responsividade, na medida em que as ações respondem a ações desencadeadas na rede de inter-relações e também irão desencadear outras ações responsivas aos demais atores dessa rede relacional. Portanto, a noção de responsividade está estritamente relacionada à alteridade, ao outro, pois é na relação com o outro que os indivíduos se constituem. Essa noção está presente também no discurso de senhor Aparecido quando se preocupa com o outro que ao esperar a Lua e perder o tempo das águas, acaba também "perdendo a safra".

No entanto, as falas dos agricultores Nivaldo e Aparecido demarcam outras duas características de certo modo relacionadas. A primeira delas é o não isolamento de variáveis na observação e explicação de um fenômeno. Nesse sentido não apenas a Lua é evocada na dependência da produção do campo, mas toda a natureza. Tudo faz parte de tudo, por isso o monismo caracteriza esse saber tradicional. Paralelamente, ao não fragmentar a realidade, como faz a ciência eurocêntrica, as explicações dos homens e mulheres do campo consideram que a natureza só tem significado se compreendida em todas as suas dimensões. Um holismo que, de certa forma, exige uma espécie de equilíbrio entre as partes, permite ao camponês acreditar, por exemplo, que a Lua resgatará o desenvolvimento da planta cultivada mesmo com a falta da chuva, afinal, "A Lua comanda tudo né?!".

Chamamos atenção ainda para outra característica menos explícita nos trechos anteriores, mas demarcadas nas falas a seguir. Trata-se do fator (des)conhecido, ou seja, a não necessidade de explicar e conhecer todos os fenômenos que ocorrem na natureza. Observamos então a entrevista do senhor José Maria quando perguntado sobre a existência de influências da Lua em suas práticas de cultivo.

Sentido por mim, as [plantas] que nasce à toa aí, que não tem época de planta, vai crescendo direto, e demora dar. Eu plantei aqui um caroço de abacate quando eu vim pra cá. Com 3 anos deu 150 abacates e não aguentou a carga. Na casa de minha cunhada tem um pé de abacate lá. [Ela] fala: vou corta esse trem aqui que não dá nada não. Eu falei: é a época que cês planto, não dá não. Tem que espera. [...] Na casa de outro, veio me fala e me mostrou um pé de jaca. Ele falou o tamanho e nunca deu. E na casa de seu Pedro tem [um pé] pequeno e deu 12 jacas. É a época de planta né? O pezim é piquinim, 
mas deu 12 jaca, e o que tá formado é a época que planto ele aí. Desde menino eu tenho experiência com roça, e meu pai era muito trabalhador. Mexia com todo tipo de roça e eu aprendi com ele.

$[\ldots]$

É na Lua forte, goma é no forte da Lua. Tira goma, fazer rapadura, fazer farinha é a mesma coisa. No forte da Lua dá mais aumento né, é tanta coisa que até biscoito, na Lua ruim, fica muchin e na Lua boa dá um biscoitão. Rapadura eu fazia direto. Eu tinha dois tachos, um tacho de garapa, sem reforma [adição de açúcar] dava 10 rapaduras na Lua forte, e na Lua fraca pra dá 10 tinha que pôr 20 litros de garapa a mais pra poder da as 10, minguava 2. Eu falo isso pro povo, mas eles não acreditam, mas trabalho com roça desde idade de 8 anos. A Lua governa tudo quanto há, só não governa 4 meses: maio, junho, julho e agosto, aí pode tirar madeira porque não governa não. [...] (senhor José Maria).

O senhor José Maria, sujeito apontado como o mais experiente da comunidade de Riacho dos Cavalos (a $9 \mathrm{~km}$ de distância do centro de Rio Pardo de Minas, é uma das maiores comunidades da cidade, pois conta com aproximadamente 150 famílias), com 85 anos de idade, carrega consigo uma bagagem de conhecimentos, técnicas e amor ao campo. É grande referência em sua comunidade, participando da sua fundação há 42 anos, sempre viveu e trabalhou no campo. Até sua aposentadoria produzia milho, feijão, arroz, cana-de-açúcar para a fabricação de rapadura e, principalmente, a mandioca para a produção em pequena escala de polvilho e farinha, produzida em tenda (nome dado pelos camponeses a uma pequena fábrica).

Diferentemente da ciência eurocêntrica que buscaria explicações para a não reprodução do pé de abacate da cunhada de senhor José Maria, ou da alta taxa de reprodução do pé da mesma fruta em sua propriedade, o conhecimento tradicional convive bem com o "por que não...?”. Além disso, o senhor José Maria não se preocupa em questionar o porquê dos diferentes rendimentos em luas distintas, basta saber que " $A$ Lua governa tudo quanto há".

Portanto, enquanto a ciência construída na modernidade e ensinada na escola se preocupa incessantemente em encontrar respostas para tudo o que nos rodeia através da análise sistemática da natureza, por assumir que a natureza é totalmente cognoscível, o conhecimento tradicional consegue conviver harmoniosamente com o (des)conhecido. Aceitar que a natureza apresenta dimensões incognoscíveis é um exercício de humildade por parte dos povos do campo, que a partir do momento em que se compreendem humanos, reconhecem que é impossível conhecer tudo que há para saber. A não pretensão de dominar o conhecimento, característica existente no saber dos povos tradicionais do campo, permite que aceitem com tranquilidade a existência de coisas inexplicáveis à luz de sua rede de conhecimento tradicional. O desconhecido, longe de demonstrar a ignorância dos povos do campo como poderia ser interpretado a partir da racionalidade da ciência canônica, presente no conhecimento tradicional denota outra relação entre os 
fenômenos e suas explicações que fogem da relação causal da ciência.

Por fim, uma das marcas que não encontramos explicitamente no conjunto de informações obtidas por esses entrevistados ${ }^{5}$, mas é inseparável de suas visões de mundo e, em consequência, dos conhecimentos tradicionais e práticas sociais desenvolvidas pelos camponeses é a espiritualidade.

O espírito é um atributo de tudo no universo. De uma perspectiva indígena, é um desafio falar sobre coisas vivas e não vivas (bióticas e abióticas), como o faz um currículo de ciências. Vivo versus não-vivo é uma dicotomia eurocêntrica [...], os povos indígenas experimentam e participam do mundo natural não apenas com sua mente, mas com seu espírito e suas emoções como também do seu corpo. (Aikenhead, \& Michell, 2011, p. 76, tradução nossa).

[...] a espiritualidade é sobre produzir sentido, a crença em um elevado poder ou propósito, um sentido de totalidade, cura, interconexão de todas as coisas, o desenvolvimento contínuo da identidade e como as pessoas constroem conhecimento através de símbolos, imagens, música, etc. (Kanu, 2011, pp. 103-104) ${ }^{6}$.

Aqui é importante deixar claro que não se trata de uma religião ou crença em uma doutrina específica, mas, por assim dizer, de uma fé ativa e não contemplativa em um fluxo permanente de "algo" que perpassa os sujeitos, os fenômenos físicos e não físicos e tende a buscar equilíbrio e harmonia na existência. A espiritualidade não é um atributo do indivíduo ou se encerra nele de modo isolado, ela está presente em todas as coisas. Por vezes pode ser evocada como manifestação da ação de Deus ou da Natureza, outras vezes naquilo que nos torna mais humanos, isto é, nas atitudes e posições que tomamos no dia a dia quando assumimos a alteridade. Tomando emprestado o conceito de Mauss, da dádiva, é na espiritualidade que se "misturam as almas nas coisas, misturam-se as coisas nas almas. Misturam-se as vidas, e assim as pessoas e as coisas misturadas saem cada qual de sua esfera e se misturam (Mauss, 2017, p. 221).

\section{Considerações finais}

Assumindo o pressuposto do ensino intercultural de ciências, assim como o diálogo de saberes nos processos formativos de educadores do campo, admitimos que é preciso integrar os conhecimentos tradicionais no currículo de ciências a partir de estratégias que demarquem as fronteiras e os contextos de uso entre o tradicional e

5 A inexistência da marca/característica espiritualidade no conjunto de dados aqui apresentados se deve à natureza das questões de investigação conduzidas em nossos roteiros de pesquisa. Uma vez que nossos mapeamentos buscavam conhecer a existência de uma realidade (a influência da Lua em práticas sociais no campo), a natureza de nossas questões visava muito mais o "o que?” e o “como?” dessas práticas do que o seu "por quê?”. Assim, avaliamos que são nas explicações de seus processos de compreensão (por que pensa assim) que estariam mais claros os aspectos da espiritualidade visto que esta marca pressupõe um sentido de propósito às coisas.

6 Estas duas citações diretas que empregamos no corpo do texto referem-se a reflexões dos autores sobre a visão de mundo de populações indígenas (aborígenes). No nosso caso, ao fazermos essa transposição para justificar a marca da espiritualidade, levamos em conta que a espiritualidade que tratamos não possui contornos tão nítidos como de comunidades indígenas, mas são vestígios que se (re)afirmam por fazer presente nas práticas sociais do campo. 
o científico e que por meio de seus pontos de contato, interculturalmente, estimule o intercâmbio e o enriquecimento mútuo.

As características e marcas dos conhecimentos tradicionais que destacamos, isto é, local, monista, holístico, relacional responsivo, (des)conhecido, validade, dinâmico, sistematicamente empírico, temporalidade e espiritualidade fazem parte de um esforço intercultural de descentramento cultural, de reconhecimento de outras formas de pensar e agir sobre e com o mundo e de dar potência epistêmica aos discursos dos de baixo. São antes uma tomada de posição contrária às adjetivações negativas (primitivos, de senso comum, de estado bruto, irracionais, inferiores, ignorantes, impuros, atrasados, supersticiosos) daquilo que não pertence ao científico do que uma mera enumeração do que pertence ou não ao domínio do tradicional.

Deste modo, se de um lado temos a intenção de dar visibilidade e empoderar os conhecimentos tradicionais no Ensino de Ciências por meio da explicitação de suas características, de outro lado é preciso ter em mente que essas marcas não podem ser compreendidas como isoladas, estanques ou descontextualizadas. O procedimento analítico que busca uma compreensão dos conhecimentos tradicionais não se confunde com a existência destes discursos em suas e por meio de suas comunidades que os enunciam/praticam.

$\mathrm{O}(\mathrm{um})$ entendimento que desenvolvemos dos conhecimentos tradicionais está em um caminho intermediário entre o que eles são para seus comunitários e o que eles são para nós (educadores envolvidos com o ensino de ciências). Provavelmente estamos bem mais próximos de descrevê-los do nosso ponto de vista do que do deles em função das dificuldades de se desencravarmos com algum sucesso da (cultura) ciência escolar, tão natural e familiar para professores de ciências. Mesmo assim, consideramos essa tarefa, em um certo sentido de tradução com todos os riscos que ela possa carregar, imprescindível para justificar em termos do currículo, território de disputas, a defesa dos conteúdos tradicionais como meta da ciência escolar.

Neste texto, optamos por privilegiar o desenvolvimento do argumento teórico a favor da integração de saberes na perspectiva intercultural do que propriamente sua análise empírica. As informações que são objeto de nossa exposição têm o propósito de tornar mais claras as colocações teóricas que desenvolvemos. Isso não quer dizer que nossa defesa é especulativa ou abstrata. Ao contrário, faz parte de nossas vivências na formação inicial e continuada de professores de ciências para o campo. Assim, em trabalhos posteriores, há a intenção de deslocar a centralidade da análise para interações em sala de aula no contexto da Educação Básica e Superior, investigações de práticas sociais situadas, observações participantes em comunidades do campo, dentre outras.

Acreditamos que a integração de saberes colabore para diminuir as desigualdades sociais, políticas e epistemológicas cometidas com populações que constroem e regem suas vidas a partir dos conhecimentos tradicionais. Defendemos que a integração de saberes pode contribuir para um diálogo mais efetivo e pode promover empoderamento das comunidades de onde se originam a partir da visibilidade do legado cultural 
e epistemológico que estas comunidades têm a deixar. Além disso, esperamos que a integração de saberes aliada à perspectiva intercultural para além de cumprir seu papel cognitivo e prático, possui "maior potencial para cooperação baseada em respeito mútuo entre comunidades tradicionais e comunidades científicas, preservando a autonomia dos processos de produção de conhecimento e buscando possibilidades de diálogo e complementaridade" (El-Hani, 2018, p. 6).

A integração de saberes tem o potencial de trazer, apropriando-nos da expressão empregada por Arroyo (2014), a diversidade de verdades em contraposição à dicotomia saber verdadeiro $v s$ saber falso, bem como a integração de saberes tem o potencial de trazer a pluralidade de sujeitos de produção de conhecimentos em contraposição à dicotomia coletivos produtores e meros consumidores do saber verdadeiro. Ainda assim, a integração de saberes não é vista por nós como nova utopia ou estratégia salvadora, mas é uma resposta concreta para todos que, como nós, que assumimos a perspectiva intercultural no Ensino de Ciências, pois, afinal, haveria interculturalidade sem trocas entre culturas?

\section{Agradecimentos}

Aos licenciandos do campo, Diones Ferreira Carvalho e Railton Oliveira Silva, bolsistas de iniciação científica, da Universidade Federal do Triângulo Mineiro (UFTM).

Ao Conselho Nacional de Desenvolvimento Científico e Tecnológico (CNPq) e à Fundação de Amparo à Pesquisa do Estado de Minas Gerais (FAPEMIG) pelo apoio à iniciação científica.

\section{Referências}

Aikenhead, G. S. (2009). Educação científica para todos. Lisboa: Edições Pedago.

Aikenhead, G., \& Michell, H. (2011). Bridging Cultures: indigenous and scientific ways of knowing nature. Toronto: Pearson.

Alentejano, P. R. (2003). As relações campo-cidade no Brasil do século XXI. Terra Livre, 2(21), 25-39.

Argueta, A. (2015). Os saberes e as práticas tradicionais: conceitos e propostas para a construção de um campo transdisciplinar. In C. Udry, \& J. S. Eidt (Eds.), Conhecimento tradicional: conceitos e marco legal (pp. 177-199). Brasília: Embrapa.

Arroyo, M. G. (2014). Outros sujeitos, outras pedagogias. Petrópolis, RJ: Vozes.

Bakhtin, M. (2010). Problemas da poética de Dostoiévski. Rio de Janeiro: Forense Universitária.

Brandão, C. R. (2012). A comunidade tradicional. In J. B. A. Costa, \& C. L. Oliveira (Orgs.), Cerrados, Gerais, Sertão: comunidades tradicionais nos sertões roseanos (pp. 363-380). São Paulo: Intermeios. 
Brito, I. C. A. (2012). Geraizeiros em movimento. In J. B. A, Costa, \& C. L. Oliveira (Orgs.), Cerrados, Gerais, Sertão: comunidades tradicionais nos sertões roseanos (pp. 335-349). São Paulo: Intermeios.

Candau, V. M. (2008). Direitos humanos, educação e interculturalidade: as tensões entre igualdade e diferença. Revista Brasileira de Educação, 13(37), 45-56. http://dx.doi. org/10.1590/S1413-24782008000100005

Carrara, A. A. (2007). Reconversão Agroextrativista: perspectiva e possibilidades para o norte de Minas Gerais. (Dissertação de Mestrado em Desenvolvimento Sustentável). Universidade de Brasília, Brasília.

Chassot, A. (2016). Alfabetização Científica: questões e desafios para a educação. Ijuí: Unijuí.

Coordenadoria de Inclusão e Mobilização Sociais, \& Ministério Público de Minas Gerais. (2018). Direitos dos povos e das comunidades tradicionais. Recuperado de https:// caa.org.br/media/publicacoes/PUBLICACAO_ESPECIAL_DIREITOS_DOS_POVOS_E_ COMUNIDADES_TRADICIONAIS_oibAP6o.pdf

Crepalde, R. S., \& Aguiar Jr., O. G. (2014) Abordagem intercultural na educação em ciências: da energia pensada à energia vivida. Educação em Revista, 30 (3), 43-61. http:// dx.doi.org/10.1590/S0102-46982014000300003

Crepalde, R. S., Klepka, V., \& Halley, T. O. P. (2017). Interculturalidade e conhecimento tradicional sobre a Lua na formação de professores no/do campo. Revista Brasileira de Educação do Campo, 2(3), 836-860. https://doi.org/10.20873/uft.25254863.2017v2n3p836

Cunha, M. C. (2009). Relações e dissensões entre saberes tradicionais e saber científico. In M. Carneiro da Cunha (Org.), Cultura com aspas (pp. 301-310). São Paulo: Cosac Naify.

Cunha, M. C., \& Almeida, M. W. B. (2009). Populações tradicionais e conservação ambiental. In M. Carneiro da Cunha (Org.), Cultura com aspas (pp. 277-300). São Paulo: Cosac Naify.

El-Hani, C. (2018). Integrando conhecimentos científicos e tradicionais na conservação. Recuperado de https://darwinianas.com/2018/05/01/integrando-conhecimentoscientificos-e-tradicionais-na-conservacao/

Flores, V., Barbisan, L. B., Finatto, M. J. B., \& Teixeira, M. (2009). Dicionário de Linguística da Enunciação. São Paulo: Contexto.

Instituto Brasileiro de Geografia e Estatística. (2018). História do município Rio Pardo de Minas (MG). Recuperado de https://cidades.ibge.gov.br/brasil/mg/rio-pardo-de-minas/ historico 
Kanu, Y. (2011). Integrating Aboriginal Perspectives into School Curriculum: Layering at Five Levels of Classroom Practice. In Y. Kanu (Org.), Integrating Aboriginal Perspectives into the school curriculum: purposes, possibilities and challenges (pp. 95-119). Toronto: University of Toronto Press.

Mauss, M. (2017). Ensaio sobre a dádiva: forma e razão da troca nas sociedades arcaicas. In M. Mauss (Org.), Sociologia e Antropologia (pp. 191-330). São Paulo: Ubu Editora.

Mortimer, E. (2001). Perfil conceptual: formas de pensar y hablar en las clases de ciencias. Infancia y aprendizaje, 24(4), 475-490. https://doi.org/10.1174/021037001317117402

Mortimer, E. F., Scott, P., Amaral, E. M. R., \& El-Hani, C. N. (2014). Conceptual Profiles: Theoretical-Methodological Bases of a Research Program. In E. F. Mortimer, \& C. N. El-Hani, (Orgs.), Conceptual Profiles: A Theory of Teaching and Learning Scientific Concepts (pp. 3-33). Dordrecht: Springer.

Nogueira, M. C. R. (2009). Gerais a dentro e afora: identidade e territorialidade entre os Geraizeiros do Norte de Minas Gerais. (Tese de Doutorado em Antropologia Social). Universidade de Brasília, Brasília.

Porto-Gonçalves, C. W. (2014). Descolonizar o pensamento, condição para a sustentabilidade: diálogo com Carlos Walter Porto-Gonçalves. Sustentabilidade em Debate,5(3), 159-168.

Santos, W. L. P., \& Mortimer, E. F. (2000). Uma análise de pressupostos teóricos da abordagem C-T-S (Ciência - Tecnologia - Sociedade) no contexto da educação brasileira. Ensino Pesquisa em Educação em Ciências, 2(2), 110-132. http://dx.doi. org/10.1590/1983-21172000020202

Silva, A. T. R. (2015). A conservação da biodiversidade entre os saberes da tradição e a ciência. Estudos Avançados, 29(83), 233-259. http://dx.doi.org/10.1590/S010340142015000100012

Xavier, P. M. A., \& Flôr, C. C. C. (2015). Saberes populares e educação científica: um olhar a partir da literatura na área de ensino de ciências. Ensino em Pesquisa Educação em Ciências, 17(2), 308-328. http://dx.doi.org/10.1590/1983-21172015170202 
Rodrigo dos Santos Crepalde

https://orcid.org/0000-0001-7025-7010 Universidade Federal do Triângulo Mineiro Uberaba, Minas Gerais, Brasil rodrigocrepalde@gmail.com

\section{Verônica Klepka}

[ำ https://orcid.org/0000-0002-9937-9852 Universidade Federal do Triângulo Mineiro Uberaba, Minas Gerais, Brasil veronicaklepka@gmail.com

Tânia Halley Oliveira Pinto [Dttps://orcid.org/0000-0002-1368-4451 Universidade Federal do Triângulo Mineiro Uberaba, Minas Gerais, Brasil taniahalley@gmail.com

\section{Mikaella de Sousa}

(ㄷ) https://orcid.org/0000-0001-9092-8467 Instituto Federal do Triângulo Mineiro Ituiutaba, Minas Gerais, Brasil mikaelladesousa@hotmail.com

Submetido em 22 de Setembro de 2018 Aceito em 18 de Abril de 2019 Publicado em 21 de Maio de 2019 